\title{
The influence of strategy video game and its background music on cognitive control
}

\author{
Xiaoqing Fu' ${ }^{1}$, and Jiulin Zhang $^{* 2}$ \\ ${ }^{1}$ University for Science and Technology of Sichuan, Chengdu, China \\ ${ }^{2}$ Southwest University, Chongqing, China
}

\begin{abstract}
It has been acutely argued for decades about the exact influences of video games on players. The researchers are also unable to come to an agreement on the effects of video games on cognitive control. Some researchers found that the video games were harmful to sustained attention, working memory and cognitive flexibility. While some other researchers claimed that video game experience has a beneficial effect on visuospatial cognition, executive control functions and cognitive improvement. In order to find out the hidden factors that cause the inconsistent results in this field, present research made a strict control on the game genre, measure of cognitive control and players' subjective immersion in video games, with the hope to investigate the influence of video games on cognitive control in a more subtle way.

Forty five participants were randomly assigned into three groups in this research. One of them was control group; they were required to use the internet to search for information related to certain subject. Another was no-music game group; they were required to play a strategy game (Red star 2) without the earphone. The last was music game group; they played the same game but with earphone to enjoy the background music. All the conditions lasted for 20 min. Before the formal experiment, all participants should finish an N-back task and the performances were used as covariable in final analyses. After the experiment, they should complete a color Stroop task and the results were the index of cognitive control ability. The results showed that the no-music video game can significantly improve players' reactive control. The music video game had a significant benefit on the proactive control compared to the control group and no-music video game group. Present research indicated that when the strategy video game was played without background music, it just improved the reactive cognitive control like other kind of video games did. The background music made strategy video game more strategically, which significantly increased the proactive cognitive control ability.
\end{abstract}

\section{Introduction}

According to The twenty-ninth statistical report on Internet development in China issued by CNNIC, by the end of 2011, the number of online video game players in China had reached 324 billion (304 billion in 2010) with a growing rate at 6.6\%. Population-based samples indicate that average gaming time ranges from 7 to $13 \mathrm{~h}$ per week in children and adolescents. Playing video games has become the most popular form of entertainment for children and adolescents [1]. The popularity of video games brings to light the need for research into the possible effects of playing video games.

Much of the research on video games so far has mainly focused on their negative effects, such as the addiction [2-7] caused by games violence. There are now many studies looking at what is called pathological gaming or video game "addiction". Many researchers defined pathologic use of video games just as pathological gambling, focusing on damage to family, school, occupation, and psychological functioning [8]. Other a large number of researchers concentrated their attention on the influence of violent video games on the aggressive behavior [6,7]. Findings of experimental, correlational, and longitudinal studies claimed that video game violence can significantly increase aggressive thoughts, emotions, and behavior over both the short term and the long term $[9,10]$. In addition, a significant body of literature also indicated that playing violent video games can exacerbate attention problems [11], produce desensitization to violence and decreases in empathy [12] and helping, and decrease school performance [9].

In Recent years, scientists are increasingly beginning to examine the potential to use this immensely popular media for positive purposes
[13]. Some research showed that video game can improve a wide range of visual and spatial skills [14] and can be highly effective teachers [15]. Moreover, prosocial video games have been proved that it can promote related prosocial behaviors [16]. There is a tendency to claim that the negative effects of video games have been exaggerated in the past, and it is a good time to examine whether video games may be put to some good use [13].

Among them, the relationship between cognitive control and video game playing gains a lot of attention [17] found a negative correlation between playing video games and performance on the color-word Stroop task for both adolescents with behavior disorders and controls. [18] found that individuals with higher media violence exposure showed less activation in the anterior cingulate cortex and inferior frontal gyrus, which may indicate a failure to recruit cognitive control networks during performance of the Stroop task. In addition, Swing et al. [19] reported a positive correlation between video game experience and a composite index of symptoms related to attention deficits and hyperactivity. This kind of phenomenon revealed a unique effect of video game experience on self-reported levels of attentional impairments.

Correspondence to: Jiulin Zhang, Southwest University, Chongqing, China; E-mail: 465725008@qq.com

Key words: strategy video game, background music, reactive cognitive control, proactive cognitive control

Received: December 29, 2016; Accepted: January 23, 2017; Published: January 27,2017 
But on the contrary, immense amounts of concrete research got an opposite result. Green et al. [20] found that video game players exhibited superior visual performance on a variety of attention-demanding tasks, including spatial target localization, rapid target identification, and multi-object tracking. Video game players may have greater control over task switching as well as better temporal attentional processing [21]. Castel et al. [22] suggested that video game players may have a benefit in higher-level executive control ability, allowing for more efficient control and allocation of selective attention. What's more, Bailey [23] found that violent gamers appeared to have a greater span of apprehension and visual short-term memory capacity compared to non-gamers and nonviolent gamers, and this improvement can be observed with as little as 10-hour of video game training [24,20].

Several factors may account for these inconsistent results in this field. At first, the measure of cognitive control ability has not been unified. Some researchers believe that the cognitive control can be divided into several minor elements and measured separately. So many researchers have tried to study the cognitive control ability on the basis of its each component, such as attention allocation and switch ability [21,22,25-32].

However, some other researchers conducted their research about the influence of video games on cognitive control ability based on the proactive or reactive modes of cognitive control from the Dual Mechanisms of Cognitive Control Theory $[6,23,33]$. The diverse focus to the cognitive control ability would concededly lead to divergent results.

The second reason is that the video games used in researches are diverse in genres.

Caldwells [34] once claimed that a crucial problem in the study of video games is that they cannot be regarded as a consistent medium. Taken as a whole, the field of video games can hardly be considered as uniform-or consistent [35]. In view of this kind of situation, different researchers deployed different types of video games when examining their influence on the cognitive control ability. They include violent video games [20,21,23,25,26,28,29,31,36]. Different genres of games, even different subgenres of games, deployed diverse abilities [34]. It is no doubt that they got different even opposite results from experiment.

Another neglected factor that could cause the distinct results may be the players' immersive state in video games. Immersion is one aspect of the experience of playing video games and is widely held to be important to the overall success of a game [37] and it reflects an illusion of nonmediation between the player and the gaming environment, so that the player feels directly obsessed in the virtual surroundings and the story happening there [38]. Immersion is confessedly viewed as part of game experience that is vital in understanding the relationship between players and the game experience. Different immersive states in video games directly had different effects on the influence of video games content on the players [39]. However, previous researchers seldom considered this important uncertainty in their experiments. So it is necessary to see whether players will behave differently when they are involved in different attractive video games.

\section{Present study}

In order to find out the hidden reasons that caused the inconsistent results when exploring the effects of video games on cognitive control ability, we conducted a research on the basis of the three possible confusion variables mentioned above.
In present research, three groups of participants were randomly chosen. Before the gameplay, all of them should finish an N-back task. Then one group was treated as control group and asked to search information related to air traffic controllers through internet on the computers for $20 \mathrm{~min}$. Another group was asked to play a kind of strategy video game (Red Alert 2) but without headphones for 20 min. The last group did just the same as the above group except with headphones during gameplay to enjoy the game background music. After finishing this procedure, they were asked to finish a classic colorStroop task. The performance in Stroop task was just the index of cognitive control ability.

The control group was used with the purpose to make the results more convincing. The participants in control group worked on a computer, but not playing any computer game, thus not enabling as many cognitive processes as those in the experimental conditions. This procedure also allowed for any conclusions to be drawn from this experiment to be attributed to the condition not by practice effects [40].

The strategy video game was employed in present study because it would exert a special effect on the cognitive control ability. Most studies on the perceptual effects of video games in recent years have utilized a particular genre, that of the fast-action first-person shooter (FPS). However, it is misleading to base conclusions about video games in general on a single genre. These results underline the importance of studying the cognitive and perceptual consequences of video games in terms of the types of skills demanded from the particular video game [41]. Just as discussed above, different video games genre would have a different influence on the cognitive control ability $[21,25,26]$. First-person video games may specifically increase individuals' ability to deploy selective attention, but not their ability to resist proactive interference from prior situations. Experience and training in demanding high-interference video games might result in a different set of abilities than in action video games [21]. For example, some research showed that visuospatial processing appears to be mainly influenced by first-person shooter games [42], while strategy games may improve cognitive control ability [23].

Compared to other kind of video games, the strategy video game has its own features. It is different from other genres of video games that emphasize the ongoing play of contextualization [35]. The strategy video game requires the constant attention and performance of the player, and that require a more distant approach characterized by intervention [21]. The player has to manipulate the simulation as it progresses through time in order to get the result with the most utility. So this may involve long periods of surveillance, where the player makes no direct interventions [35]. That is to say, the players in strategy video games even cannot lower their vigilance for a moment until they finished the whole game. So they has to constantly perform kinaesthetic actions, manipulate the controller, following the visual cues supplied by the screen [35]. This highly and persistently concentrated mind state will inevitable exert a much more significant influence on cognitive control ability, especially on proactive control ability $[29,33]$.

The Stroop task was used in this study as a measure of the proactive and reactive cognitive control ability based on the Dual Mechanisms of Cognitive Control Theory [29]. This theory holds that individuals can engage in either proactive or reactive modes of cognitive control depending on environmental demands and individual differences [43]. Proactive control relies upon the anticipation and prevention of interference before it occurs, whereas reactive control relies upon the detection and resolution of interference after its onset [44]. Because 
strategy video game is characterized as a constant engagement with overwhelming amounts of information and it creates a constant cascade of cognitive shocks that require immediate responses [35]. So it is justified to assume that strategy video game would generate a more significant effect on the proactive cognitive control than reactive control.

Anecdotal evidences [33,45] suggest that the classic color-Stroop task is a sensitive and valid way to separately measure the proactive and reactive control ability. It taps a specific cognitive control ability, inhibition: ignoring task-irrelevant information in order to respond on the basis of task-relevant information [46]. In the Stroop task results, the conflict adaptation effect serves as an index of proactive control [47]. This effect represents the difference in response time for an incongruent trial when that trial is preceded by a congruent trial or an incongruent trial (i.e., substracting response time for incongruentincongruent trials from response time for congruent-incongruent trials). Reactive control is measured by the Stroop interference effect [43]. It represents a slower response time for incongruent trials relative to congruent trials (i.e., substracting response time for incongruent trials from response time for congruent trials).

At last, the two experiment groups (one with earphone, the other not) were used in this research mainly for investigating the role of players' subjective immersion in the influence of strategy video game on cognitive control. Immersion is one aspect of the experience of playing video games and is widely held to be critical to the overall success of a video game [37]. It is likely that most regular video game players have experienced some degree of immersion [48]. Immersion could increase or decrease the carryover effects of game content into real-world outcomes as a function of need satisfaction, and also can serve as a key moderating variable that amplifies the effects of virtual content on actual goals and decision making [49].

Background music plays a significant role in the immersive quality of a video game [50]. It may give players the impression of a realistic space by presenting virtual offscreen sources [51]. Morris [52] claimed that background music in video game was used to provide an audio complement to action on the screen and to create a sense of a real physical space. All sounds in the video game contribute in some way to player immersion in the acoustic ecology [53]. By tightly linking game play and music, the player can become much more immersed in the experience [54]. So in present study, the two experiment groups, which shared same game content but different at whether or not the background music appeared, were employed with the purpose of testing its influence on the cognitive control through its influence on players' subjective immersion.

\section{Method}

\section{Participants}

45 male college students were recruited through ads on the campus net work. The candidates should meet following requirements: 1 . Familiar with Red Alert 2; 2. Right handed; 3. Normal hearing ability. The average age for this sample was $20.78(\mathrm{SD}=1.63)$ years. The average video game play during a weekday was $1.43(\mathrm{SD}=1.02)$ hours and the average video game play during the weekend was 2.63 ( $\mathrm{SD}=$ 1.79) hours, and the three groups did not have a significant difference at the whole play time at every week, $\mathrm{F}(2,37)=1.44, \quad \mathrm{p}=0.25$.

\section{Materials}

Game experience questionnaire: The participants' game experience was measured by this scale made by Anderson et al. [55]. Participants were asked to list their 3 favorite video games and rate how violent and how often they play the game each week. The total score were the index of participants' game experience and used as covariants in final analysis.

Strategy video game: The game that was used in present study was a classic strategy video game - Red Alert 2, which was designed by West-wood studios (2000). The purpose of this video game is to build a military base to defend own base from enemy attacks, and destroy the opposing army's troops and base. Participants should try to gain more money and spend it on a number of buildings (e.g., barracks, satellite, war factory), many vehicles (e.g., tanks, fighter planes, helicopters), and troops (e.g., basic infantry, engineers, attack dogs).

Red Alert 2 is a real-time strategy game that combines both the speed of real-time gaming and the complexity of turn-based strategy games. One of the important aspects of this game is that it allows for multiple ways to achieve victory. In this game, the player has to continually assess available resources, plan and expend those resources, utilize rationally the expanding territories and multiple cities to get final success.

Another important reason that the Red Alert 2 was employed was that the background music played a crucial role in the whole game. The realistic and stirring background music accompanied with the dramatic plot would make the players more involved into the game environment.

N-back task: Participants in this task are shown a list of stimuli (e.g., letters or numbers) one at a time and must judge whether or not each stimulus matches the one directly before it (1-back condition), or prior to the one before it (2-back condition), or two stimuli before it (3-back condition). The accuracy in task is a manipulation of cognitive control [23].

In this study, n-back task stimuli consisted of 26 letters (A-Z) randomly presented on a white background. Participants performed a practice block of 25 trials each for the 1-back and 2-back conditions. In the 1-back condition, participants should judge whether each letter matched the previous letter. In the 2-back condition, they were told to judge whether each letter was the same or different from the letter before the previous letter. There were two experimental blocks consisting of 20 targets and 30 non-targets for a total of 50 trials in each block.

Stroop task: A classical color Stroop task was employed in this research. In this paradigm, words stimuli consisted of a random presentation of three color names (red, green, or yellow) presented in one of these three colors. In the congruent condition, the color in which the word was presented matched the color name (e.g., the word green displayed in green color). In the incongruent condition, the color of the word presented did not match the color name (e.g., the word green displayed in red color). The participants in this task were told just to make judges according to the color of words while ignoring the color name. The test phase consisted of two blocks of 80 trials. In each block there were 40 congruent and 40 incongruent stimuli.

\section{Procedure}

All participants who entered the laboratory were requested to finish a game experience questionnaire. Upon completion, they should finish the N-back task. Then all participants were randomly assigned to three groups: the control group $(n=15)$, the without-music game 
group ( $\mathrm{n}=15)$, and the with-music game group $(\mathrm{n}=15)$. Participants in the control condition used the internet to search for information about air traffic controllers for $20 \mathrm{~min}$. This filler task was used in order to keep the participant's hand-eye coordination constant. Participants in the without-music game experimental condition played the Red star 2 for 20 min quietly without the earphone. Participants in the with-music game experimental condition also played Red Alert 2 for 20 min but those only with the earphone can enjoy the background music accompanied with game content. After $20 \mathrm{~min}$, all participants completed the color-Stroop task, and then thanked and fully debriefed.

\section{Results}

\section{Game experience}

A one-way ANOVA was conducted to examine whether the participants' game experience was significantly different from each other among the three groups. Results showed that the participants' game experience was not significantly different from each group, $\mathrm{F}(2,42)=1.44, \mathrm{p}=0.25>0.05$. That meant the game experience was not a significant contributor to the final results in present research.

\section{Reactive control}

Response time was slower for incongruent trials, $M=731.06$ $\mathrm{ms}(\mathrm{SD}=73.99)$, than congruent trials, $\mathrm{M}=638.67 \mathrm{~ms}(\mathrm{SD}=80.81)$, revealing a significant interference effect, $\mathrm{t}(44)=66.28, \mathrm{p}<.001$. Then a MANCOVA was conducted with the difference in response time between incongruent trials and congruent trials (i.e., substracting response time for incongruent trials from response time for congruent trials) in Stroop task as the dependent variable, the group as the independent variable, response time in $\mathrm{N}$-back task as covariate. Results showed a significant main effect for group, $\mathrm{F}(2,42)=3.69, \mathrm{P}<.05$. A follow-up analyses was conducted and the results showed that there was just a significant difference between the control group and the no-music game group, $\mathrm{P}=.032, \mathrm{M}_{\text {(control) }}=54.93 \mathrm{~ms}, \mathrm{M}_{\text {(no music) }}=114.29 \mathrm{~ms}$. No other significant difference was found. That was to say, the nomusic strategy video game significantly improved the players' reactive cognitive control ability compared to control group (Table 1).

\section{Proactive control}

To examine the influence of experiment conditions on proactive control, a MANCOVA was conducted with the conflict adaptation effect (i.e., substracting response time for incongruent-incongruent trials from congruent-incongruent trials with nonrepetitions) used as the dependent variable. The experimental condition and the N-back scores were separately used as independent variable and covariate. Results showed a significant main effect for group, $\mathrm{F}(2,42)=4.87$,

Table 1. means and standard deviations of response time in Stroop task.

\begin{tabular}{|l|c|c|c|c|}
\hline & \multicolumn{2}{|c|}{ Incongruent trials (ms) } & \multicolumn{2}{c|}{ Congruent trials (ms) } \\
\hline Item & $\mathrm{M}$ & $\mathrm{SD}$ & $\mathrm{M}$ & $\mathrm{SD}$ \\
\hline Control group & 746.10 & 71.22 & 681.17 & 106.93 \\
\hline Without-music group & 763.02 & 54.45 & 626.86 & 47.40 \\
\hline With-music group & 684.06 & 73.94 & 607.99 & 61.23 \\
\hline
\end{tabular}

Table 2. means and standard deviations ofresponse time of incongruent trials in Strooptask.

\begin{tabular}{|c|c|c|c|c|}
\hline \multirow[b]{2}{*}{ Item } & \multirow{2}{*}{$\begin{array}{c}\begin{array}{c}\text { Incongruent- } \\
\text { incongruent }\end{array} \\
\mathrm{M}\end{array}$} & \multirow{2}{*}{$\begin{array}{c}\text { trials(ms) } \\
\mathrm{SD}\end{array}$} & \multicolumn{2}{|c|}{$\begin{array}{c}\text { Congruent-incongruent trials } \\
(\mathrm{ms})\end{array}$} \\
\hline & & & $\mathrm{M}$ & SD \\
\hline Control group & 669.35 & 80.32 & 822.85 & 77.35 \\
\hline Without-music group & 680.06 & 68.78 & 845.99 & 92.51 \\
\hline With-music group & 668.52 & 78.80 & 699.60 & 144.10 \\
\hline
\end{tabular}

$\mathrm{P}<.05$. A further examination demonstrated that there were significant differences between the music game group and the no-music game group, $\mathrm{P}=.02$, and between music game group and control group, $\mathrm{P}=.04, \mathrm{M}_{\text {(control) }}=153.50 \mathrm{~ms}, \mathrm{M}_{\text {(no music) }}=165.94 \mathrm{~ms}, \mathrm{M}_{\text {(music) }}=31.08 \mathrm{~ms}$. That was to say, the strategy video game with background music significantly improved the players' proactive cognitive control ability (Table 2).

\section{Discussion}

In order to find out the hidden factors that cause the arguments about the influence of video games on cognitive control, this research made some subtle controls on the possible factors that could exert effects on the final results. In present research, we insisted that those vibrant "factors" were included three aspects: distinct at the measure of cognitive control, diverse in game genres and different players' subject immersive state during gameplay.

In the aspect of measure of cognitive control, based on the Dual Mechanisms of Cognitive Control Theory [29], this study employed a classic color-Stroop task to test separately the influence of video game on the proactive and reactive cognitive control. The video game used in this research was Red Alert 2, a classic kind of strategy video game. Because some research has demonstrated that different video game genres would exert different effect on the cognitive control $[21,25,26]$ and the strategy video game, due to its specific characters, may have peculiar effects on the proactive and reactive cognitive control $[21,35]$. A large amount of previous research showed that the background music plays a significant role in the immersive quality of a video game [50,51]. So in present study, one group was employed to hear the background music and the other group not, in order to detect the role of subjective immersion in the influence of video games on the cognitive control.

The results showed that the no-music strategy video game can significantly improve the players' reactive cognitive control compared to the control group. Besides, the strategy video game with background music can significantly improve the players' proactive cognitive control ability compared to both the control group and the video game group without background music.

On one hand, the results indicated that the strategy video games without background music just exerted same effects as other kind of video games: a significant improvement at reactive cognitive control. Theoretically, owning to its characteristic, the strategy video game should significantly improve the proactive cognitive control $[29,33]$. But when the video game was played without background music, which made the video games much less fascinating and attractive, the players in this kind of situation would become less immersive into the game environment and plot. As a result, they are not likely to make a thorough plan for fear of the enemy's unexpected attack. On the contrary, they preferred counterattack after enemy appeared within visible area, which was almost the same as other kind of video games (such as Action game, Role-playing game). These kinds of video games required players to make responses as soon as possible to stimuli appeared on the screen [56]. They also reinforced players to quickly modify their behavior when conflict was experienced (i. e., an enemy was encountered). This attribute of these kind of video games leaded to the suggestion that high gamers were less likely to employ proactive control and more likely to employ reactive control [33]. For example, Bailey [23] found that violent video games encouraged and enhanced the use of reactive control, so the players may employ reactive control more efficiently than the non-gamers. The result of present research showed that strategy video games if played without background music just had a similar impact on cognitive control as other kind of video 
games that had been widely discussed in other numerous studies $[21,26]$.

On the other hand, the result of this research also demonstrated that the background music made the strategy video game like a real "strategy" video game. The background music plays a significant role in the immersive quality of a video game [50]. And it is often used in video game to provide an audio complement to action on the screen and to create a sense of a real physical space [52]. The player can become much more immersed in the experience when the video game be linked with related background music [54]. In present study, when the strategy video game was played with its own background music, the players became much more immersive into the game content. So at the beginning of the game, the players would make a comprehensive plan for the whole round. Due to the special features of strategy video game, the players tended to manipulate the operation as it progresses through time in order to get the result with the most utility and can not lower their vigilance for a moment until they finished the whole game. This highly and persistently concentrated mind state will inevitable exert a much more significant influence on cognitive control ability, especially on proactive control ability $[29,33]$.

However, there was a point that cannot be ignored was that all the improvements caused by the video game were its short term effect. This was an important factor that can explain why it got a different result compared to other similar research. The video games would exert different effects on cognitive ability through short term and long term training [51]. Bailey et al. [33] found that the high levels of video game consumption may be associated with a reduction at proactive cognitive control. In this study, the participants were divided into two groups (high gamers and low gamers) according to their video game experience in daily life. So it was focused on the long term effect of video game. In present research, a Stroop task was offered to participants after they played game for $20 \mathrm{~min}$ (control group surfed internet for $20 \mathrm{~min}$ ) and the results were used as the index of cognitive control ability. So the changes in cognitive control ability of players were the short effects of strategy video game. In this respect, it is possible that game benefits might reflect shifts in strategy rather than changes in more basic cognitive or perceptual capacities. Nelson et al. $[41,57,58]$ found that short-term game exposure did appear to produce strategy changes [10]. But some researchers claimed that they offered solid evidences that the video game had an increase in cognitive performance both in short term and long term $[6,51]$. This is an important question that should be made clearly in the future. But overall, in present research the strategy video game did improve players' certain kind of cognitive control, at least in short term.

\section{Limitations and future works}

Like all studies, there are still weaknesses of this study that need to be addressed.

First of all, the measurement of cognitive control may be a little simple. Though the color-Stroop paradigm has been proved to be a classic way to investigate the cognitive control ability, it is still necessary to employ some other more advanced and objective measures (such as ERP or fMRI) to get a more convincing result in the following studies. In addition, because present study aimed to investigate the short term effect of video games, all the participants just played the game for $20 \mathrm{~min}$. Maybe this duration is not long enough for a significant improvement of cognitive control. So it is interesting to conduct a longer game time research to see whether it would exert different influences on cognitive control. Besides these, future researchers also can continue this study to discuss the effect of strategy video games on cognitive control from multiple angles based on different theories.

\section{References}

1. Gross ML (2010) Advergames and the effects of game-product congruity. Computers in Human Behavior 26: 1259-1265.

2. Van Rooij AJ, Schoenmakers TM, Vermulst AA, Van den Eijnden RJ, Van de Mheen D (2011) Online video game addiction: identification of addicted adolescent gamers. Addiction 106: 205-212. [Crossref]

3. Weinstein AM (2010) Computer and video game addiction-a comparison between game users and non-game users. Am J Drug Alcohol Abuse 36: 268-276. [Crossref]

4. Han DH, Hwang JW, Renshaw PF (2010) Bupropion sustained release treatment decreases craving for video games and cue-induced brain activity in patients with Internet video game addiction. Exp Clin Psychopharmacol 18: 297. [Crossref]

5. Sherry J (2007) Violent Video games and aggression: why can't we find effects? Mass media effects research: advances through meta-analysis. 231-248.

6. Barlett CP, Rodeheffer C (2009) Effects of realism on extended violent and nonviolen video game play on aggressive thoughts, feelings, and physiological arousal. Aggress Behav 35: 213-224. [Crossref]

7. Adachi P, Willoughby (2011) The effect of violent video games on aggression: Is it more than just the violence? Aggression and Violent Behavior 16: 55 - 62 .

8. Anderson CA, Gentile DA, Dill KE (2012) Prosocial, antisocial, and other effects of recreational video games. Handbook of children and the media 2: 249-272.

9. Bijvank MN (2008) Violent Video Game Effects on Children and Adolescents: Theory, Research, and Public Policy. Child and Adolescent Mental Health 13: 99-100.

10. Anderson CA, Shibuya A, Ihori N, Swing EL, Bushman BJ, et al. (2010) Violent video game effects on aggression, empathy, and prosocial behavior in eastern and western countries: a meta-analytic review. Psychol Bull 136: 151. [Crossref]

11. Swing EL, Gentile DA, Anderson CA, Walsh DA (2010) Television and video game exposure and the development of attention problems. Pediatrics 126: 214-221. [Crossref]

12. Carnagey NL, Anderson CA, Bushman BJ (2007) The effect of video game violence on physiological desensitization to real-life violence. Journal of Experimental Social Psychology 43: 489-496.

13. Ferguson CJ (2010) Introduction to the special issue on video games. Review of General Psychology 14: 66

14. Achtman RL, Green CS, Bavelier D (2008) Video games as a tool to train visual skills. Restor Neurol Neurosci 26: 435-446. [Crossref]

15. Gentile DA, Gentile JR (2008) Violent video games as exemplary teachers: A conceptual analysis. Journal of Youth and Adolescence 37: 127-141.

16. Greitemeyer T, Osswald S (2010) Effects of prosocial video games on prosocial behavior. J Pers Soc Psychol 98: 211-221. [Crossref]

17. Kronenberger WG, Mathews VP, Dunn DW, Wang Y, Wood EA, et al. (2005) Media violence exposure and executive functioning in aggressive and control adolescents. $J$ Clin Psychol 61: 725-737. [Crossref]

18. Mathews VP, Kronenberger WG, Wang Y, Lurito JT, Lowe MJ, et al. (2005) Media violence linked to concentration, self-control. Journal of Computer Assisted Tomography 29: 287-292.

19. Swing EL (2008) Attention abilities, media exposure, school performance, personality, and aggression. ProQuest.

20. Green CS, Bavelier D (2007) Action-video-game experience alters the spatial resolution of vision. Psychol Sci 18: 88-94. [Crossref]

21. Karle JW, Watter S, Shedden JM (2010) Task switching in video game players: Benefits of selective attention but not resistance to proactive interference. Acta Psychol (Amst) 134: 70-78. [Crossref]

22. Castel AD, Pratt J, Drummond E (2005) The effects of action video game experience on the time course of inhibition of return and the efficiency of visual search. Acta Psychol (Amst) 119: 217-230. [Crossref]

23. Bailey K (2009) Individual differences in video game experience: Cognitive control, affective processing, and visuospatial processing.

24. Feng J, Spence I, Pratt J (2007) Playing an action video game reduces gender difference 
in spatial cognition. Psychological Science 18: $850-855$.

25. Wu S, Cheng CK, Feng J, D'Angelo L, Alain C, et al. (2012) Playing a first-person shooter video game induces neuroplastic change. $J$ Cogn Neurosci 24: 1286-1293. [Crossref]

26. Franceschini S, Gori S, Ruffino M, Viola S, Molteni M, et al. (2013) Action video games make dyslexic children read better. Curr Biol 23: 462-466. [Crossref]

27. Maclin EL, Mathewson KE, Low KA, Boot WR, Kramer AF, et al. (2011) Learning to multitask: Effects of video game practice on electrophysiological indices of attention and resource allocation. Psychophysiology 48: 1173-1183. [Crossref]

28. Mishra J, Zinni M, Bavelier D, Hillyard SA (2011) Neural basis of superior performance of action videogame players in an attention-demanding task. $J$ Neurosci 31: 992-998. [Crossref]

29. Basak C1, Boot WR, Voss MW, Kramer AF (2008) Can training in a real-time strategy video game attenuate cognitive decline in older adults? Psychol Aging 23: 765-777. [Crossref]

30. Dye MW, Green CS, Bavelier D (2009) The development of attention skills in action video game players. Neuropsychologia 47: 1780-1789. [Crossref]

31. Colzato LS, van Leeuwen PJ, van den Wildenberg WP, Hommel B (2010) DOOM'd to Switch: Superior Cognitive Flexibility in Players of First Person Shooter Games. Front Psychol 1: 8. [Crossref]

32. Green CS, Pouget A, Bavelier D (2010) Improved probabilistic inference as a general learning mechanism with action video games. Curr Biol 20: 1573-1579. [Crossref]

33. Bailey K, West R, Anderson CA (2010) A negative association between video game experience and proactive cognitive control. Psychophysiology 47: 34-42. [Crossref]

34. Caldwell N (2004) Theoretical frameworks for analysing turn-based computer strategy games. Media International Australia 110: 42-51

35. Apperley TH (2006) Genre and game studies: Toward a critical approach to video game genres. Simulation \& Gaming 37: 6-23.

36. Boot WR, Blakely DP, Simons DJ (2011) Do action video games improve perception and cognition? Front Psychol 2: 226. [Crossref]

37. Seah ML, Cairns P (2008) From immersion to addiction in videogames. In Proceedings of the 22nd British HCI Group Annual Conference on People and Computers: Culture, Creativity, Interaction- British Computer Society 1: 55-63

38. Rigby S (2004) Player Motivational Analysis: A model for applied research into the motivational dynamics of virtual worlds. Motivation Research Group, University of Rochester, Rochester, NY.

39. Hou J, Nam Y, Peng W, Lee KM (2012) Effects of screen size, viewing angle, and players' immersion tendencies on game experience. Computers in Human Behavior 28: 617-623.

40. Barlett CP, Vowels CL, Shanteau J, Crow J, Miller T (2009) The effect of violent and non-violent computer games on cognitive performance. Computers in Human Behavior 25: $96-102$

41. Nelson RA, Strachan I (2009) Action and puzzle video games prime different speed accuracy tradeoffs. Perception 38: 1678. [Crossref]
42. Dye MW, Green CS, Bavelier D (2009) The development of attention skills in action video game players. Neuropsychologia 47: 1780-1789. [Crossref]

43. Braver TS, Gray JR, Burgess GC (2007) Explaining the many varieties of working memory variation: Dual mechanisms of cognitive control. Variation in working memory $76-106$.

44. Bailey K, West R, Anderson CA (2011) The association between chronic exposure to video game violence and affective picture processing: An ERP study. Cogn Affect Behav Neurosci 11: 259-276. [Crossref]

45. Kerns JG, Cohen JD, MacDonald AW 3rd, Cho RY, Stenger VA, et al. (2004) Anterior cingulate conflict monitoring and adjustments in control. Science 303: 1023-1026. [Crossref]

46. Prabhakaran R, Kraemer DJ, Thompson-Schill SL (2011) Approach, Avoidance, and Inhibition: Personality Traits Predict Cognitive Control Abilities. Pers Individ Dif 51: 439-444. [Crossref]

47. Botvinick MM, Cohen JD, Carter CS (2004) Conflict monitoring and anterior cingulate cortex: an update. Trends $\operatorname{Cogn}$ Sci 8: 539-546. [Crossref]

48. Brockmyer JH, Fox CM, Curtiss KA, McBroom E, Burkhart KM, et al. (2009) The development of the Game Engagement Questionnaire: A measure of engagement in video game-playing. Journal of Experimental Social Psychology 45: 624-634.

49. Przybylski AK, Rigby CS, Ryan RM (2010) A motivational model of video game engagement. Review of General Psychology 14: 154.

50. Collins K (2008) Game sound: an introduction to the history, theory, and practice of video game music and sound design. MIT Press.

51. Jørgensen K (2006) On the functional aspects of computer game audio. Jaeggi, Buschkuehl, Jonides \& Shah, 2011. Short- and long-term benefits of cognitive training

52. Morris SJ (2002) First Person Shooters: A Game Apparatus. In: Krzywinkska, Geoff King and Tanya (Ed.) Screenplay: Cinema/Videogame/Interface. London, Wallflower Press.

53. Grimshaw M, Schott G (2008) A conceptual framework for the analysis of first-person shooter audio and its potential use for game engines. International Journal of Computer Games Technology 5.

54. Nelson C, Wünsche BC (2007) Game/music interaction: an aural interface for immersive interactive environments. In Proceedings of the eight Australasian conference on User interface. Australian Computer Society, Inc. 64: 23-26

55. Anderson CA, Dill KE (2000) Video games and aggressive thoughts, feelings, and behavior in the laboratory and in life. J Pers Soc Psychol 78: 772-790. [Crossref]

56. Montag C, Flierl M, Markett S, Walter N, Jurkiewicz M, et al. (2011) Internet addiction and personality in first-person-shooter video gamers. Journal of Media Psychology: Theories, Methods, and Applications 23: 163.

57. Boot WR, Kramer AF, Simons DJ, Fabiani M, Gratton G (2008) The effects of video game playing on attention, memory, and executive control. Acta Psychol (Amst) 129 . 387-398. [Crossref]

58. The development of the Game Engagement Questionnaire: A measure of engagement in video game-playing. Journal of Experimental Social Psychology 45: 624-634.

Copyright: (C2017 Fu X. This is an open-access article distributed under the terms of the Creative Commons Attribution License, which permits unrestricted use, distribution, and reproduction in any medium, provided the original author and source are credited. 